\title{
Relationship between Adverse Childhood Experiences and Resiliency among College Students
}

\author{
Glory Okwori
}

College of Public Health, East Tennessee State University, U.S.

\section{ABSTRACT}

Background: Adverse childhood experiences (ACEs) are associated with negative outcomes, however, there are factors that can mitigate the effects from exposure to ACEs. This study examined the prevalence of adverse childhood experiences (ACEs), characteristics of resilient individuals and the association between ACE scores, resiliency and other factors among college students.

Subjects and Method: A cross-sectional survey was completed in 2018. Frequencies were calculated for the number and types of ACE experienced by participants. Bivariate relationships between characteristics of participants and resilience were examined using Chi-square tests. The independent relationship between ACE scores and resiliency factors was examined using ordinal logistic regression. The dependent variable was ACE score. An ordinal logistic regression model examined the relationship between conventional ACE scores and resilience levels and other factors.

Results: There were 570 study participants. Seventy-one percent of study participants had experienced at least one conventional ACE, and 98\% had experienced at least one expanded ACE. Individuals with high resilience had lower conventional ACE scores and better health. Females $(\mathrm{OR}=1.67 ; 95 \% \mathrm{CI}=1.14$ to 2.45$)$ were more likely to have higher conventional ACE scores. Participants living in suburban areas compared to rural areas $(\mathrm{OR}=0.61 ; 95 \% \mathrm{CI}$ : 0.43 to 0.85 ), and children raised with both parents compared to single parents $(\mathrm{OR}=0.17$; $95 \% \mathrm{CI}=0.12$ to 0.25 ) were less likely to have higher conventional ACE scores. Gender (OR= $0.54 ; 95 \% \mathrm{CI}=0.35$ to 0.82 ) and general health status $(\mathrm{OR}=1.5 \mathrm{O} ; 95 \% \mathrm{CI}=1.05$ to 2.13$)$ were the only significant predictors of the expanded ACE scores.

Conclusion: Findings identify important resilient traits such as relationships, selfcontrol, internal beliefs, and initiative,. as well asportray the high prevalence ofACEs and the importance of resilience as a protective factor in reducing ACEs.

Keywords: adverse childhood experiences, resilience, mitigate

\section{Correspondence:}

Glory Okwori. East Tennessee State University. 1276 Gilbreath Dr., Box 70300, Johnson City, TN. Email: okwori@etsu.edu.

\section{Cite this as:}

Okwori G (2021). Relationship between Adverse Childhood Experiences and Resiliency among College Students. J Epidemiol Public Health. 06(01): 83-97. https://doi.org/10.26911/jepublichealth.2021.06.01.09. cC (i) (-) Journal of Epidemiology and Public Healthis licensed under a Creative Commons cc)

\section{BACKGROUND}

Adverse Childhood Experiences (ACEs) are complex population health issues with notable detrimental outcomes. The seminal study by Felitti and Anda defined ACEs as 10 types of childhood abuse, neglect and family dysfunction or exposure to toxic stress occurring before age 18 (Felitti et al., 1998). ACEs can alter the body chemistry of children and alter the brain structure. Prolonged exposure to stress from ACEs may lead to recurring abnormal regulation of the autonomic nervous system and the stress response system and to persistent increases in inflammatory response (Anda et al., 1999; Dube et al., 2002, 2003). This can cause impaired decision making, loss of 
memory, learning difficulties and behavioral problems (Shonkoff et al., 2012).

The original ACE study found linkages between ACEs and depression, alcoholism, smoking, drug abuse, heart disease and obesity (Anda et al., 1999; Dube et al., 2002, 2003). The rates of dropout from school and poverty were significantly higher for individuals with three or more ACEs (Brogden and Gregory, 2019). Individuals are also more vulnerable to serious conditions later in life, and the sequelae of ACEs occur in adulthood (Felitti et al., 1998; Danese et al., 2009; Fuller-Thomson and Brennenstuhl, 2009).Also, ACEs have been linked to decreased health-related quality of life (HRQOL) and increased utilization of healthcare services (Edwards et al., 2007).

Some limitations of the original study by Anda and Felitti have been identified as follows: the narrow operationalization of the ACE measure does not adequately represent the social distribution of adversities, the misrepresentation of adversities across childhood by highlighting adult outcomes, and failure to include protective measures. Thus, it was stated that future research should take account of these limitations in order to fully comprehend how protective measures, social context and adversity interact to affect behavior and health(McEwen and Gregerson, 2019).

Although the consequences of ACEs may seem disparaging, there are protective factors that can help to increase resiliency and reduce the effects of exposure to ACEs. Conditions of chronic stress lead to an accumulation of toxic stress when protective factors are weak or lacking which can negatively affect children's development and consequently their life trajectories (Center on the Developing Child at Harvard University, 2016). Protective factors, especially supportive relationships and caring adults, are imperative in counterbalancing the negative effects of ACEs (National Scientific Council on the Developing Child, 2015).Despite extreme stressors, resilient individuals are able to recover and function well at school and work. Research examining the impact of resilience on children exposed to traumatic or adverse events is limited (Gartland et al., 2019). Future studies on protective factors such as resilience on survivors of childhood trauma are needed to understand the impact of these adverse events and provide understanding into how to improve functioning for individuals (Howell and Miller-Graff, 2014).

To fully understand the pathways through which childhood adversity occurs, ACEs must be correctly classified among multiple contexts. In a study by Cronholm et al., the authors noted that relying on the conventional ACEs as defined by the seminal ACE study would have underrepresented the prevalence of ACEs, and the study helped to identify additional ACEs to incorporate the interplay among personal, family and community factors (Cronholm et al., 2015).

Research on ACEs has emphasized that adult community samples and studies using younger populations are needed to depict causal mechanisms in the association between ACEs and long-term outcomes. Hence, research on college students can expand studies on the ACEs pathway into younger years and evaluate a population with unique needs and characteristics (Khrapatina and Berman, 2017; Arnett, 2019). Furthermore, the relationship between resilience and self-rated health has not been adequately studied and exploring this relationship for individuals who have experienced ACEs will link ACEs, resilience and health throughout the lifespan (PérezZepeda et al., 2016). The objectives of this study are to examine the characteristics 
Okwori et al./ Adverse Childhood Experiences and Resiliency among College Students

associated with resiliency and the relationship between ACE scores, resiliency and health measures among university students.

\section{SUBJECTS AND METHOD}

\section{Study Design}

This study utilized a cross-sectional survey designed to assess ACEs, resilience and health status at East Tennessee State University (ETSU). The data were collected through electronic surveys programmed through Checkbox software. The ACEs and resilience survey was created from existing, validated surveys including the Centers for Disease and Control and Prevention (CDC) - Kaiser ACE study, Philadelphia ACE study and health status questions from the CDC HRQOL module, as well as the Devereux Adult Resilience Survey (DARS). The survey took about 20 minutes to complete.

\section{Population and Sample}

This study surveyed students (aged $\geq 18$ years) at ETSU during the fall semester of 2018. The survey was advertised via email communicated through the ETSU VicePresident's office and participants were recruited through the email. ETSU is a midsized, regional university whose mission involves educating rural, first-generation college students and the underserved.

\section{Study Variables}

The outcome variable in this study was the total ACE score. The independent variable and protective factor in this study was resilience. Additional variables examined included HRQOL questions related to selfrated health such as general health status, physical unhealthy days, mental unhealthy days, and painful days that impeded one's ability to function. Other variables included gender, residence, family structure and employment.

\section{Operational Definition of Variables}

Participants received 1 point per question if they responded yes to the ACE questions. The aggregate ACE separate scores were calculated as the sum of "yes" responses across the questions that pertain to the conventional ACE scale (10 questions) and the expanded ACE scale (5 questions), respectively. ACE scores were categorized utilizing traditional Kaiser coding: o Conventional ACEs, 1-3 Conventional ACEs, and $\geq 4$ Conventional ACEs. Expanded ACE scores had the following categories : o Expanded ACEs, 1-2 Expanded ACEs, and $\geq 3$ Expanded ACEs (Cronholm et al., 2015). The ACE scale has been shown to have good test reliability and retrospective reporting (Dube et al., 2004).

The questions regarding resilience were dichotomized reflecting whether or not individuals had these characteristics, and 1 point was awarded for each affirmative response. The maximum total score overall was 23 points. Resiliency was categorized as low $(<18)$ versus high $(\geq 18)$ resilience. This was based on comparing scoring for other ACEs resiliency scales which showed an $80 \%$ or higher as indicating high resilience since scoring was not provided for DARS (Smith et al., 2013; Young-Wolff et al., 2019).

General health status was defined by asking participants whether their overall health was excellent, very good, good, fair or poor. Physical unhealthy days and mental unhealthy days were defined by asking participants how many days during the past month was their physical health or mental health bad which was categorized as either none or 1 or more days. Painful days were defined by asking participants how many days during the past month did pain make it difficult to perform their usual activities which was dichotomized to reflect 
whether or not participants experienced 1 or more painful days.

Family structure was operationalized as a dichotomous variable reflecting whether or not children lived with a single parent or more than one parent. Employment was operationalized as a dichotomous variable reflecting whether or not students worked for more than or less than 20 hours a week.

\section{Study instrument}

The original (conventional) ACE study questionnaire consisted of 10 yes/no questions about adverse childhood experiences before age 18 and included 10 total categories: 3 categories of abuse (physical, emotional and sexual), 2 categories of neglect (physical and emotional) and 5 categories of family and household dysfunction (parental separation, incarceration, substance abuse, mental illness and battered mother) (Dube et al., 2001). The expanded ACE scale includes questions on community-level adversity (witnessing violence, discrimination, bullying, foster care and adverse neighborhood experience) (Cronholm et al., 2015).

Resilience was measured using a 23item scale known as the DARS consisting of four subscales. This survey assesses the following domains: relationships, internal beliefs, initiative and self-control. The DARS has shown adequate psychometric properties such as adequate convergent validity and internal consistency (Ball and Mackrain, 2008). In the current study, Cronbach's alpha for the DARS was 0.86 . Total scoring is usually not provided, and there are no suggested guidelines. The purpose of the DARS is to provide knowledge on areas of personal strengths and need (Mackrain, 2013). Thus, each of the subscales were also analyzed to provide more specific information.

\section{Data Analysis}

Descriptive summaries of ACE scores and types of ACEs were generated. Key characteristics of high resilient study participants were examined. Pearson's chi-square tests or Fisher's exact tests were utilized for categorical variables. Univariate ordinal logistic regression was used to examine the independent relationship between total ACE scores, resiliency, health measures and certain demographic characteristics since the dependent variable was classified according to the order of its magnitude. An ordinal logistic regression model was constructed to evaluate the relationship between total resilience and total conventional ACE scores after controlling for health measures and sociodemographic characteristics. The most widely used ordinal logistic regression model in biomedical and epidemiological practice is the proportional odds model (Ananth and Kleinbaum DG, 1997). Assumptions testing was conducted, and a partial proportional odds model was used (Lall et al., 2002; O'Connell, 2011). Thus, all covariates in the model had a proportional odds structure except for general health status which had a different parameter for each response function.

Data from three participants were excluded because over $40 \%$ of items were left unanswered. Analyses were conducted on complete cases considering the fact that a missing rate of less than $5 \%$ is inconsequential and analysis is less likely to be biased when less than $10 \%$ of the data are missing (Schafer, 1999; El-Masri and FoxWasylyshyn, 2005). All analyses were conducted using SAS (Version 9.4. SAS Institute Inc., Cary, NC, USA).

\section{Research Ethics}

The study was reviewed and approved by the ETSU Institutional Review Board and the approval letter was obtained from the 
Okwori et al./ Adverse Childhood Experiences and Resiliency among College Students

research ethics committee in August 2018. Informed consent was received from all study participants.

\section{RESULTS}

Summaries of total ACE scores as well as the types of ACEs are presented in figure 1. Of the 570 participants in the study sample, less than one third (29\%) reported no experience with conventional ACEs. Less than half (44\%) of respondents experienced between one and three conventional ACEs and $27 \%$ experienced 4 or more ACEs.
Approximately 2\% of participants reported no experience with expanded ACEs and over half (55\%) of the sample experienced 3 or more expanded ACEs. The least common type of ACEs was neglect (29\%) while almost all participants had experienced at least one adversity in their community (99\%). Forty percent of participants had experienced at least one form of abuse, and approximately $65 \%$ of participants had experienced one form of adversity within their household.

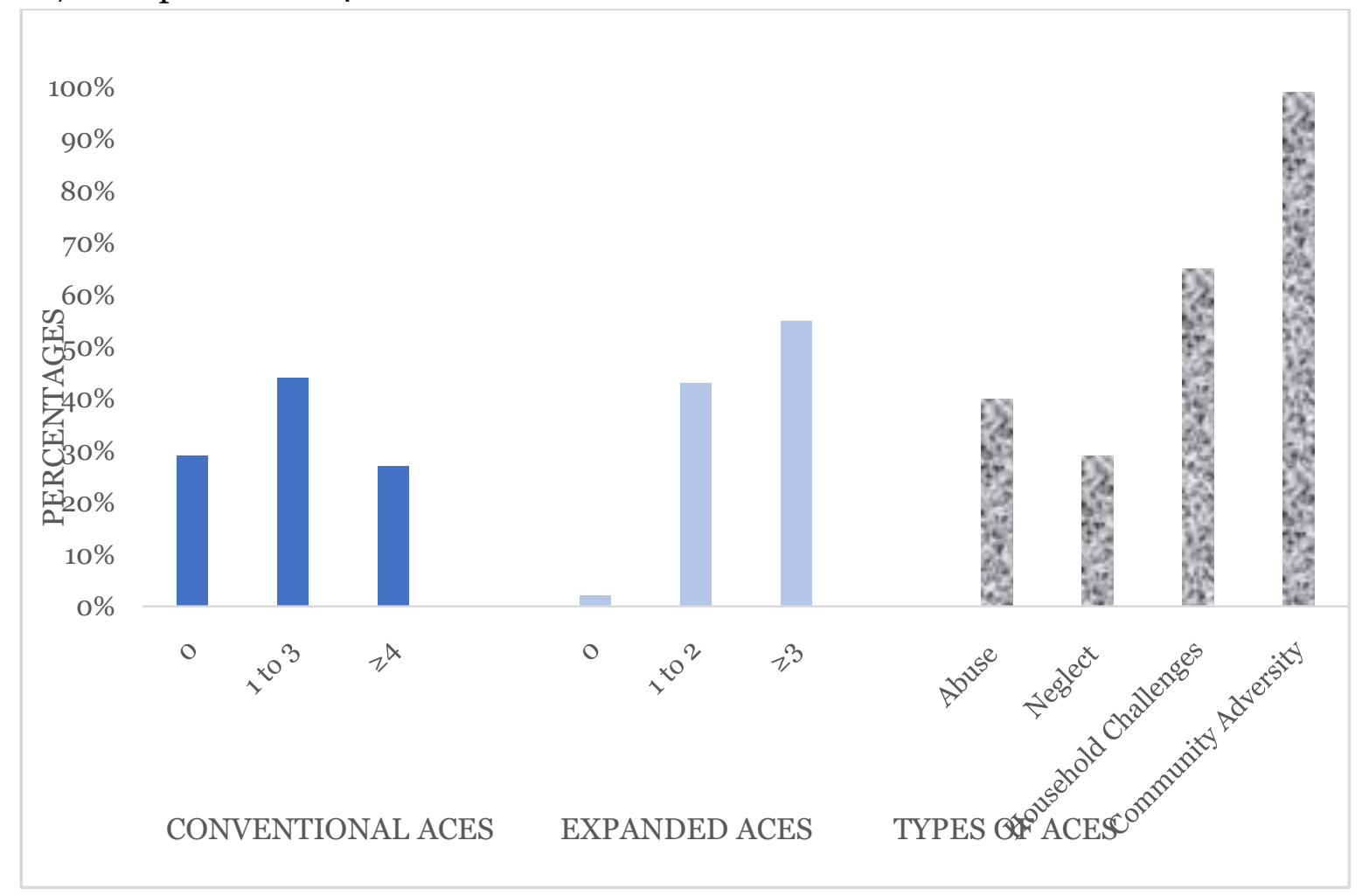

\section{Figure 1. Prevalence of ACES}

Approximately $40 \%$ of the study sample had high resilience and 60\% had low resilience (Table 1). Seventy-seven percent of highly resilient individuals were females while seventy-two percent of low resilient individuals were females $(p=$ o.010). Among highly resilient individuals, $75 \%$ grew up with more than one parent and $25 \%$ grew up in single-parent homes, while among low resilient individuals, 66\% grew up with more than one parent and $33 \%$ grew up in single-parent homes $(\mathrm{p}=0.011)$.

Among highly resilient individuals, 42\% had zero conventional ACE scores, 40\% had conventional ACE scores between 1 and 3 and $18 \%$ had conventional ACE scores greater than 4, while among individuals with low resilience, $21 \%$ had zero conventional ACE scores, 47\% had 
Okwori et al./ Adverse Childhood Experiences and Resiliency among College Students

conventional ACE scores between 1 and 3 expanded ACE scores between 1 and 2 and and $31 \%$ had conventional ACE scores greater than $4(\mathrm{p}<0.001)$. Although not $56 \%$ had expanded ACE scores greater than

$3(\mathrm{p}=0.974)$.

significant, $43 \%$ of study participants had

Table 1. Characteristics of high resilient vs low resilient individuals

\begin{tabular}{|c|c|c|c|c|}
\hline & \multicolumn{2}{|c|}{$\begin{array}{c}\text { Overall Resilience Level } \\
\text { N (\%) }\end{array}$} & \multirow{2}{*}{$\begin{array}{l}\text { Total } \\
\text { (N\%) }\end{array}$} & \multirow{2}{*}{$\mathbf{p}$} \\
\hline & Low & High & & \\
\hline & $\mathrm{N}=344(60.4 \%)$ & $\mathrm{N}=226(39.7 \%)$ & $\mathrm{N}=570$ & \\
\hline \multicolumn{5}{|l|}{ Demographics } \\
\hline Gender & & & & 0.010 \\
\hline Male & $72(21.3)$ & $52(23.0)$ & $124(22.0)$ & \\
\hline Female & $243(71.9)$ & $173(76.6)$ & $416(73.8)$ & \\
\hline Residence of childhood & & & & 0.398 \\
\hline Urban & $41(12.2)$ & 29 (12.9) & $70(12.5)$ & \\
\hline Sub urban & $133(39.6)$ & $78(34.7)$ & $211(37.6)$ & \\
\hline Rural & $162(48.2)$ & $118(52.4)$ & $280(49.9)$ & \\
\hline \multicolumn{5}{|l|}{ Other characteristics } \\
\hline Family Structure & & & & 0.011 \\
\hline Two parents & $226(65.7)$ & $169(74.8)$ & 395(69.3) & \\
\hline One parent & $112(32.6)$ & $57(25.2)$ & $169(29.7)$ & \\
\hline Employment & & & & 0.756 \\
\hline Full Time & $125(36.3)$ & $95(42.0)$ & $220(38.6)$ & \\
\hline Part Time & $118(34.3)$ & $71(31.4)$ & $189(33.2)$ & \\
\hline None & $95(27.6)$ & $60(26.6)$ & $155(27.2)$ & \\
\hline Conventional ACEs & & & & $<0.001$ \\
\hline \multicolumn{5}{|l|}{ Score } \\
\hline $\mathrm{O}$ & $65(21.2)$ & $93(41.9)$ & 158(29.9) & \\
\hline $1-3$ & $145(47.4)$ & $88(39.6)$ & $233(44.1)$ & \\
\hline$\geq 4$ & $96(31.4)$ & $41(18.5)$ & $137(26.0)$ & \\
\hline Expanded ACEs & & & & 0.974 \\
\hline o & $1(0.3)$ & $1(0.5)$ & $2(0.4)$ & \\
\hline $1-2$ & $132(43.1)$ & $96(43.2)$ & $228(43.2)$ & \\
\hline$\geq 3$ & $173(56.5)$ & $125(56.3)$ & $298(56.4)$ & \\
\hline \multicolumn{5}{|l|}{ Health Measures } \\
\hline General Health & & & & $<0.001$ \\
\hline Excellent/Very Good & $158(45 \cdot 9)$ & $164(72.6)$ & $322(56.5)$ & \\
\hline Good & $118(34.3)$ & $54(23.9)$ & $172(30.2)$ & \\
\hline Fair/Poor & $58(16.9)$ & $8(3.5)$ & $66(11.6)$ & \\
\hline Physical Unhealthy Days & & & & 0.001 \\
\hline None & $219(65.6)$ & $178(78.8)$ & $397(70.9)$ & \\
\hline $1 /$ more days & $115(34.4)$ & $48(21.2)$ & $163(29.1)$ & \\
\hline Mental Unhealthy Days & & & & $<0.001$ \\
\hline None & $64(19.3)$ & $105(46.9)$ & $169(30.4)$ & \\
\hline $1 /$ more days & $268(80.7)$ & $119(53.1)$ & $387(69.6)$ & \\
\hline Painful Days & & & & 0.034 \\
\hline None & $248(73.8)$ & $183(81.0)$ & $431(76.7)$ & \\
\hline $1 /$ more days & $88(26.2)$ & 43(19.0) & $131(23.3)$ & \\
\hline
\end{tabular}

Among highly resilient individuals, $73 \%$ reported excellent or very good general health and $4 \%$ reported poor general health, while among individuals with low resilience, $46 \%$ reported excellent or very good general health and $17 \%$ reported poor 
general health $(\mathrm{p}<0.001)$. Among high resilient individuals, approximately $79 \%$ reported zero days of not having good physical health within the past 30 days compared to $66 \%$ of individuals with low resilience $(\mathrm{p}=0.001)$. High resilient individuals reported having a higher number of zero days of not having good mental health within the past 30 days than low resilient individuals ( $47 \%$ vs $19 \%$, respectively, $\mathrm{p}<$ o.001). High resilient individuals reported lesser number of days where pain made it difficult to perform their usual activities compared to low-resilience individuals (19\% vs 26\%, respectively, $\mathrm{p}=0.034$ )

Findings from the bivariate ordinal regression analysis are shown in Table 2. The total conventional ACEs score were examined first. For individuals with a low resilience score overall, the odds of an ACE score greater than 4 versus between 1 and 3 are 2.38 greater when compared to individuals with high resilience. The same increase is found between the categories of having an ACE score between 1 and 3 and an ACE score of o. Examining the subscales of the DARS survey revealed similar significant positive associations for low resilient individuals within the relationship, internal beliefs, initiative and self-control scales. Females were more likely to have higher conventional ACE scores than males. Individuals who grew up in suburban regions were less likely to have high ACE scores compared to individuals who grew up in rural regions. Individuals who grew up with 2 parents were $83 \%$ less likely to have high ACE scores compared to individuals who grew up with single parents.

For individuals whose general health was not excellent or very good, the odds of greater than 4 ACEs versus 1-3 ACEs are 3 times greater (Table 2). Likewise, the odds of having an ACE score between 1 and 3 versus $\mathrm{O}$ are 3 times greater. Physical unhealthy days, mental unhealthy days and painful days were also positively associated with higher ACE scores. Furthermore, the expanded ACEs scores were examined next in the bivariate analyses. Female individuals and general health status showed significant associations with expanded ACE scores.

Table 2. Binary ordinal logistic regression of total ACE scores

\begin{tabular}{|c|c|c|c|c|}
\hline & $\begin{array}{c}\begin{array}{c}\text { Conventional } \\
\text { ACEs Score }\end{array} \\
\text { OR (95\% CI) }\end{array}$ & $\begin{array}{c}\begin{array}{c}\text { Expanded } \\
\text { ACEs Score }\end{array} \\
\mathbf{p}\end{array}$ & OR (95\% CI) & $\mathbf{p}$ \\
\hline \multicolumn{5}{|l|}{ Resilience } \\
\hline Overall Resilience & $2.38(1.71-3.31)$ & $<0.001$ & $1.01(0.71-1.43)$ & 0.948 \\
\hline Relationship Resilience & $2.02(1.46-2.82)$ & $<0.001$ & $0.99(0.70-1.41)$ & 0.975 \\
\hline Internal Beliefs & & $<0.001$ & & 0.600 \\
\hline Resilience & $2.11(1.53-2.92)$ & & $0.91\left(0.65^{-1.29}\right)$ & \\
\hline Initiative Resilience & $1.72(1.23-2.40)$ & $<0.001$ & $1.04(0.73-1.48)$ & 0.850 \\
\hline Self-Control Resilience & $2.47(1.67-3.64)$ & $<0.001$ & $1.41(0.94-2.12)$ & 0.095 \\
\hline \multicolumn{5}{|l|}{ Sociodemographic } \\
\hline Gender & $1.67(1.14-2.45)$ & 0.010 & $0.54(0.35-0.82)$ & 0.004 \\
\hline Urban Residence & $1.26\left(0.75^{-2.13}\right)$ & 0.383 & $0.67(0.38-1.18)$ & 0.164 \\
\hline Sub urban Residence & $0.61(0.43-0.85)$ & 0.004 & $1.29(0.89-1.87)$ & 0.179 \\
\hline Family Structure & $0.17(0.12-0.25)$ & $<0.001$ & $1.34(0.92-1.96)$ & 0.129 \\
\hline Employment & $1.17(0.79-1.73)$ & 0.437 & $1.33(0.87-2.03)$ & 0.191 \\
\hline \multicolumn{5}{|l|}{ Health Measures } \\
\hline General Health & $3.07(2.19-4.29)$ & $<0.001$ & $1.50\left(1.05^{-2.13}\right)$ & 0.024 \\
\hline Physical Unhealthy Days & $1.62(1.14-2.30)$ & 0.010 & $1.46(1.00-2.15)$ & 0.053 \\
\hline Mental Unhealthy Days & $2.62(1.84-3.72)$ & $<0.001$ & $1.35\left(0.93^{-1.95)}\right.$ & 0.115 \\
\hline Painful Days & $2.25(1.53-3.31)$ & $<0.001$ & $1.41(0.92-2.14)$ & 0.112 \\
\hline
\end{tabular}


Okwori et al./ Adverse Childhood Experiences and Resiliency among College Students

The adjusted ordinal regression analyses are presented for the conventional ACE scores in table 3. Individuals with low resilience were $73 \%$ more likely to have an ACE score of 4 or higher versus 1-3 after accounting for other characteristics. Likewise, the same increase is expected when comparing an ACE score of o versus 1-3. The results from these analyses showed that higher total conventional ACE score remained positively associated with the following factors: gender ( $\mathrm{AOR}=1.50,95 \%$
$\mathrm{CI}=1.01,2.25)$, mental unhealthy days $(\mathrm{AOR}=1.76,95 \% \mathrm{CI}=1.18,2.62)$ and painful days $\mathrm{AOR}=1.76,95 \% \mathrm{CI}=1.15,2.69) . \mathrm{Sub}$ urban residence and having both parents remained negatively associated with ACE score. Individuals whose health were not excellent or very good were 3 times more likely to have an ACE score greater than 4 or between 1 and 3 compared to an ACE score of $o$ given that other variables in the model are held constant.

Table 3. Multivariate regression analyses based on total conventional ACE scores

\begin{tabular}{|c|c|c|}
\hline & $\begin{array}{c}\text { Conventional ACEs Score } \\
\text { Adjusted OR (95\% CI })^{\mathrm{a}} \\
\end{array}$ & $\mathbf{p}$ \\
\hline \multicolumn{3}{|l|}{ Resilience } \\
\hline Overall Resilience & $1.73(1.20-2.50)$ & 0.003 \\
\hline \multicolumn{3}{|l|}{ Sociodemographic } \\
\hline Gender & $1.5 \mathrm{O}(1.01-2.25)$ & 0.047 \\
\hline Urban Residence & $1.32\left(0.75^{-2.31)}\right.$ & 0.337 \\
\hline Suburban Residence & $0.56(0.39-0.81)$ & 0.002 \\
\hline Family Structure & $0.16(0.11-0.24)$ & $<0.001$ \\
\hline \multicolumn{3}{|l|}{ Health Measures } \\
\hline General Health ( $1^{\text {st }}$ response function) & $1.62(1.02-2.56)$ & 0.041 \\
\hline General Health ( $2^{\text {nd }}$ response function) & $3.35(2.06-5.44)$ & $<0.001$ \\
\hline Mental Unhealthy Days & $1.76(1.18-2.62)$ & 0.005 \\
\hline Painful Days & $1.76(1.15-2.69)$ & 0.010 \\
\hline
\end{tabular}

a The multivariable model controlled for total resilience (low vs high), gender (female vs male), residence (reference: rural), family structure ( 2 vs 1 parent), general health (reference: not excellent/very good), mental unhealthy days (1 or more days vs none), painful days (1 or more days vs none).

\section{DISCUSSION}

This study examined the prevalence of (ACEs) and its relationship with resilience, health and certain sociodemographic characteristics among college students. Exposure to at least one conventional ACE was reported by $71 \%$ of study participants compared to $52 \%$ in the original study (Felitti et al., 1998). 98\% of study participants experienced adversities related to expanded ACEs alone and these findings would have gone unrecognized if conventional ACEs were examined exclusively. Other authors have noted that it would be beneficial to include the expanded ACE measures (Cronholm et al., 2015; Crouch et al., 2018). These data are relevant as author contemplate elaborating the conventional ACE measurement to improve its capacity to capture other adversities.

The finding that exposure to ACEs in this study was higher compared to studies on adult community samples is unique. A potential explanation is the fact that younger respondents who have left their childhood homes recently can recall their ACEs better than older adults (Khrapatina and Berman, 2017). Also, similar rates of ACEs in the original study are still being found by recent research on adult parti- 
cipants in the community (Centers for Disease Control and Prevention, 2010; Felitti and Anda, 2010).Further research on the types of ACEs among college students should be explored to improve understanding as this study mainly examined ACE scores.

The results show that there is an inverse relationship between low resilience and high ACE scores and the impact of ACEs on future outcomes may vary by resilience. The coping skills and strengths that such individuals possess can help them overcome traumatic experiences. Authors have highlighted protective factors related to positive adaption to include individual abilities, sense of belonging and a protective community (Narayan et al., 2018). Key elements of resiliency as reflected by the DARS scale included secure attachments to other individuals that involve emotional support and encouragement, control of one's thoughts, self-efficacy, effective decision making, and the ability to make positive choices and appropriately express one's feelings. Other authors have identified similar traits of resiliency such as high selfesteem, optimism, internal locus of control, determination, cognitive reappraisal and flexibility, and social competence (Bellis et al., 2018).

Individuals with low self-control resiliency had the greatest odds of higher conventional ACE scores. This refers to one's ability to regulate emotions and express them using appropriate actions. Although children react differently to adversity, children exposed to ACES are likely to have problems with self-regulation, focusing and interpersonal interactions. A study discovered that resilience, defined as self-control when faced with a challenge, reduced the impact of ACEs on poor school performance and grade repetition (Bethell et al., 2014).
An important aspect of social and emotional competency is learning how to recognize, regulate and express one's feelings in a healthy way. Children experience and express their emotions starting from early infancy, however assistance from an adult who is sensitive and responsive is helpful to help the child become aware of such feelings and control them. Infants who are able to recognize and express their emotions as well as develop self-regulation are better able to control their behavior as they grow older and self-regulation is associated with better resilience, coping and stress management when faced with adversity (Murray et al., 2016).

It can sometimes be difficult for children to control their feelings; however, they can learn to express such feelings in positive ways and control actions that result from such feelings. When young kids are not given the opportunity to have their emotions acknowledged or express such feelings without the fear of being punished, it becomes difficult for them to gain a sense of security and a good sense of themselves. Children need adults to support their feelings by instructing them regarding labels for feelings, acknowledging their feelings and helping them to express such emotions in appropriate ways. Particular attention is imperative to help children identify, manage and express conflicting emotions for children who may have experienced significant trauma.

The internal beliefs skills as measured by the DARS refer to the thoughts about our lives. Positive appraisal skills and expectations have been shown to be associated with resilience (Traub and BoyntonJarrett, 2017). Executive function refers to a set of skills that are similar to the components measured by the DARS scale such as internal beliefs, initiative and self-control. These skills underlie the capacity to meet 
goals, plan ahead, display self-control, follow directions, and stay focused despite interruption. Researchers have identified strong executive function to predict resilience and early childhood adversity is associated with low levels of executive function. Davidovich et al. (2016) found fewer depressive symptoms in children with improved executive function that were exposed to ACEs. Executive functioning in children can be improved with educational methods such as computer training programs and mindfulness training(Traub and Boynton-Jarrett, 2017).

Masten's framework of resilience as well as other ecological perspectives have included the community as a major component of resilience or developmental adaptation (Masten and Tellegen, 2012). An improved understanding of how socioecological resilience can mitigate the programs for individuals with high ACE scores may help to create approaches that allow for greater precision in determining the level of risk in individuals with high ACE scores (Masten and Tellegen, 2012; Narayan et al., 2018).It may also have helped to see how such measures of resilience correlated with the expanded ACE score which measured community level adversity. However, in this sample, many factors that were significant for the conventional ACEs were not significant for the expanded ACEs. This could be due to the fact that majority of the study population were whites. It has been argued that certain demographic groups are more associated with expanded ACEs but not the conventional ACEs since the conventional ACEs measures were originally developed for and measured within a predominantly white population (Cronholm et al., 2015). Future work should include community level measures of resilience and explore differences in exposure to ACEs between college attendees and those who do not attend college.

The need for young individuals to acquire education beyond high school has been largely emphasized. This continued involvement in educational training allows emerging adults to widen their social connections to groups different from their families of origin which creates new ways of living and encourages students to focus on developing unique skills (Arnett, 2019).For ACE survivors, college may be an opportunity to be distant from families that could have been sources of their adverse experiences which could explain why many factors were more significant for the conventional ACE scale than the expanded ACE scale. Thus, students are provided with more opportunities to improve their adaptive functioning or resiliency.

It would have been expected that ACEs would be higher in a rural area due to the unique health barriers rural resident experience. Researchers found that exposure to ACEs was prevalent among rural adults and ACEs were more likely to cooccur in rural areas and it is possible that there would be an elevated risk of ACEs compared to urban areas, although there is limited evidence regarding urban-rural differences (Belanger et al., 2018). Although not significant, the data suggested that urban residents were more likely to have ACEs compared to rural residents $(\mathrm{OR}=1.26,95 \% \mathrm{CI}=0.75,2.13)$. Other studies found that rural residents were less likely to experience ACEs or showed similar odds to urban residents (Talbot, Szlosek and Ziller, no date; Chanlongbutra, Singh and Mueller, 2018). However, this study showed that individuals in rural regions were more likely to have ACEs compared to suburban regions. Future studies should examine the multilevel urban/rural 
spectrum in order to provide a better perspective of the urban/rural experiences.

This study showed that individuals with more than one parent had high resilience and lower odds of high ACE scores. Research has shown that ACEs are more common among children without parental care (Bramlett and Radel, 2014). This shows that a stable home environment and frequent interaction with parents as well as positive family functioning can serve as protective factors. This supports the case for expanding resources to children from at-risk families. Family functioning has shown to be a protective factor against mental health concerns and neighborhood violence as well as other unfavorable outcomes for children exposed to ACEs (Fan and Chen, 2012; Balistreri and AlviraHammond, 2016).

The results also imply that screening for ACEs can help to identify students who have high risk for deterioration in physical and mental health. Self-rated health has repeatedly shown to be a valid marker of objective health which can predict physical activity, cognitive capacity, health care expenditure, morbidity and mortality (Pérez-Zepeda et al., 2016). Resilience was defined in a different study as good physical and mental health despite the consequences of early adversity (Liu et al., 2020)

The cross-sectional nature of this study while unique and convenient prevents assessment of causality. Respondents may have misinterpreted survey questions due to the use of self-reported data although the ACE scale has shown good retrospective reporting and improved recall for younger participants as previously stated (Dube et al., 2004; Khrapatina and Berman, 2017). The resiliency scale did not capture community level measures of resilience, although in this study, non-resilience factors were not significantly asso- ciated with the expanded ACE score which measured community level adversity. The HRQOL measures could not be measured on a continous scale due to the nature of reported data although the responses enabled a meaningful categorization. Nonetheless, the findings of this study provide additional knowledge for continued work.

Improving resiliency in young adults who have been exposed to ACEs can help to mitigate the effect of ACEs and assist them to recover, thereby promoting healthier and more productive lives. ACEs possess such a deep-seeded effect on individuals and families which can produce a ripple effect that extends to the community and cause intergenerational dysfunction. Addressing various forms of trauma will enable individuals who have experienced ACEs to succeed and break the inter-generational cycle.

Building the personal attributes of children related to resiliency such as selfregulation, self-efficacy, executive functioning, stable relationships, environmental factors and social competency, can provide protective effects against the adverse effects of ACEs. Identifying, understanding and fostering protective school, home and community factors can help to reduce the impact of ACEs. Policies and programs are needed to train service providers and educators on resilience. This can help to decrease the effect of trauma on the life course and impact young individuals at such a critical phase of development as they transition into adulthood.

AUTHOR CONTRIBUTION

Author was responsible for all research.

FUNDING AND SPONSORSHIP None. 


\section{ACKNOWLEDGEMENT}

This analysis was not funded by any direct source and had no role in this analysis, decision to publish, or preparation of the manuscript.

CONFLICT OF INTEREST

There are no conflicts of interest.

\section{REFERENCES}

Ananth C, Kleinbaum DG (1997). Regression models for ordinal responses: a review of methods and applications. Int $J$ Epidemiol. 26(6): 1323-1333. Available at: https://academic.oup.com/ije/article/26/6/1323/676893

(Accessed: 20 June 2020).

Anda RF, Croft JB, Felitti VJ, Nordenberg D, Giles WH, Williamson DF, Giovino GA (1999). Adverse childhood experiences and smoking during adolescence and adulthood. J Am Med Assoc. 282(17): 1652-1658. https://doi.org/10.1001/jama.282.17.1652.

Arnett JJ (2019) Emerging adulthood: the winding road from the late teens through the twenties. 2nd edn. Oxford University Press.

Balistreri KS, Alvira-Hammond M (2016). Adverse childhood experiences, family functioning and adolescent health and emotional well-being. Public Health. 132: 72-78. doi: 10.1016/j.puhe.2015.10.034.

Ball A, Mackrain M (2008) Devereux Adult Resilience Survey (DARS), Professional Psychology Trainee. Available at: www.CenterForResilientChildren.org.

Belanger K, Benson W, Borders T, Dalton $\mathrm{K}$, Emanuel-McClain C, Evans K, Fabre B, et al. (2018). Exploring the rural context for adverse childhood experiences (ACEs). National Advisory Committee on Rural Health and Human Services. https://www.hrsa.- gov/sites/default/files/hrsa/advisorycommittees/rural/publications/Rural -Context-for-ACEs-August2018.pdf.

Bellis MA, Hughes K, Ford K, Hardcastle KA, Sharp CA, Wood S, Homolova, L Davies A (2018). Adverse childhood experiences and sources of childhood resilience: A retrospective study of their combined relationships with child health and educational attendance. BMC Public Health. 18(1). https://doi.org/10.1186/s12889-0185699-8.

Bethell CD, Newacheck P, Hawes E, Halfon $N$ (2014). Adverse childhood experiences: Assessing the impact on health and school engagement and the mitigating role of resilience. Health Aff. 33(12): 2106-2115. https://doi.org/10.1377/hlthaff.2014.0914.

Bramlett M, Radel LF (2014) Adverse family experiences among children in nonparental care, 2011-2012. Natl Health Stat Report. Available at: https://pubmed.ncbi.nlm.nih.gov/24 806543/ (Accessed: 16 June 2020).

Brogden L, Gregory DE (2019). Resilience in community college students with adverse childhood experiences. Community Coll J Res Prac. 43(2): 94108. doi: 10.1080/10668926.2017.1418685 .

Center on the Developing Child at Harvard University (2016) From Best Practices to Breakthrough Impacts - Center on the Developing Child at Harvard University. Available at: https://developingchild.harvard.edu/resources/frombest-practices-to-breakthroughimpacts/ (Accessed: 16 June 2020).

Centers for Disease Control and Prevention (2010) Adverse childhood experiences reported by adults --- Five States, 2009, 2010. Available at: https://www.cdc.gov/mmwr/preview/mmwr 
Okwori et al./ Adverse Childhood Experiences and Resiliency among College Students

html/mm5949a1.htm (Accessed: 21 June 2020).

Chanlongbutra A, Singh GK, Mueller CD (2018). Adverse childhood experiences, health-related quality of life, and chronic disease risks in rural areas of the United States. J Environ Public Health. 2018: 7151297. https://doi.org/10.1155/2018/7151297.

Cronholm PF, Forke CM, Wade R, BairMerritt MH, Davis M, HarkinsSchwarz M, Pachter LM, Fein JA (2015). Adverse childhood experiences: Expanding the concept of adversity. Am J Prev Med. 49(3): 354-361. https://doi.org/10.1016/j.amepre.201 5.02.001.

Crouch E, Strompolis M, Radcliff E, Srivastav A (2018). Examining exposure to adverse childhood experiences and later outcomes of poor physical and mental health among South Carolina adults. Children and Youth Services Review. 84: 193-197. https://doi.org/10.1016/j.childyouth.2017.11.031.

Danese A, Moffitt TE, Harrington HL, Milne BJ, Polanczyk G, Pariante CM, Poulton R, Caspi A (2009). Adverse childhood experiences and adult risk factors for age-related disease: Depression, inflammation, and clustering of metabolic risk markers. Arch Pediatr Adolesc Med. 163(12): 11351143. https://doi.org/10.1001/archpediatrics.2009.214.

Davidovich S, Collishaw S, Thapar AK, Harold G, Thapar A, Rice F (2016). Do better executive functions buffer the effect of current parental depression on adolescent depressive symptoms?. J Affect Disord. 199: 54-64. https://doi.org/10.1016/j.jad.2016.03 .049.

Dube SR, Anda RF, Felitti VJ, Chapman DP, Williamson DF, Giles WH (2001).
Childhood abuse, household dysfunction, and the risk of attempted suicide throughout the life span: Findings from the adverse childhood experiences study. J Am Med Assoc, 286(24): 3089-3096. https://doi.org/10.1001/jama.286.24.3089.

Dube SR, Anda RF, Felitti VJ, Edwards VJ, Croft JB (2002). Adverse childhood experiences and personal alcohol abuse as an adult. Addict Behav. 27(5): 713-725. https://doi.org/10.1016/so306-4603(01)00204-0.

Dube SR, Felitti VJ, Dong M, Chapman DP, Giles WH, Anda RF (2003). Childhood abuse, neglect, and household dysfunction and the risk of illicit drug use: The adverse childhood experiences study. Pediatrics. 111(3): 564572. https://doi.org/10.1542/peds.111.3.564.

Dube SR, Williamson DF, Thompson T, Felitti VJ, Anda RF (2004). Assessing the reliability of retrospective reports of adverse childhood experiences among adult HMO members attending a primary care clinic. Child Abuse Negl. 28(7): 729-737. https://doi.org/10.1016/j.chiabu.2003.08.009.

Edwards V, Anda RF, Gu D, Dube SR, Felitti VJ (2007). Adverse childhood experiences and smoking persistence in adults with smoking-related symptoms and illness. Perm J. 11(2): 5-13. https://dx.doi.org/10.7812\%2Ftpp\%2 Fo6-110.

El-Masri MM, Fox-Wasylyshyn SM (2005). Missing data: An introductory conceptual overview for the novice researcher. Can J Nursing Res. 37(4): 156-171.

Fan Y, Chen Q (2012). Family functioning as a mediator between neighborhood conditions and children's health: Evidence from a national survey in the 
Okwori et al./ Adverse Childhood Experiences and Resiliency among College Students

United States. Soc Sci Med. 74(12): 1939-1947. https://doi.org/10.1016/j.socscimed.2012.01.039.

Felitti VJ, Anda RF, Nordenberg D, Williamson DF, Spitz AM, Edwards V, Koss MP, Marks JS (1998). Relationship of childhood abuse and household dysfunction to many of the leading causes of death in adults: The adverse childhood experiences (ACE) study. Am J Prev Med. 14(4): 245258. https://doi.org/10.1016/so7493797(98)ooo17-8.

Felitti VJ, Anda RF (2010). The relationship of adverse childhood experiences to adult medical disease, psychiatric disorders and sexual behavior: Implications for healthcare. The Impact of Early Life Trauma on Health and Disease: The Hidden Epidemic. Cambridge University Press. 77-87. https://doi.org/10.1017/CBO9780511 777042.010.

Fuller-Thomson E, Brennenstuhl S (2009). Making a link between childhood physical abuse and cancer. Cancer. 115(14): 3341-3350. https://doi.org/$10.1002 /$ cncr.24372.

Gartland D, Riggs E, Muyeen S, Giallo R, Afifi TO, MacMillan $\mathrm{H}$, Herrman $\mathrm{H}$, Bulford E, Brown SJ (2019). What factors are associated with resilient outcomes in children exposed to social adversity? A systematic review. BMJ Open. 9(4): eo24870. https://doi.org/10.1136/bmjopen-2018-024870.

Howell KH, Miller-Graff LE (2014). Protective factors associated with resilient functioning in young adulthood after childhood exposure to violence. Child Abuse and Neglect. 38(12): 19851994. https://doi.org/10.1016/j.chiabu.2014.10.010.

Khrapatina I, Berman P (2017). The impact of adverse childhood experiences on health in college students. J Child Adoles Trauma. 10(3): 275-287. https://doi.org/10.1007/s40653-016o093-0.

Lall R, Campbell MJ, Walters SJ, Morgan K (2002). A review of ordinal regression models applied on health-related quality of life assessments. Stat Methods Med Res. 11(1):49-67. https://doi.org/10.1191/o962280202sm271ra.

Liu M, Mejia-Lancheros C, Lachaud J, Nisenbaum R, Stergiopoulos V, Hwang SW (2020). Resilience and adverse childhood experiences: Associations with poor mental health among homeless adults. Am J Prev Med. 58(6): 807-816. https://doi.org/10.1016/j.amepre.2019.12.017.

Mackrain M (2013) Devereux Adult Resilience Survey (DARS). Available at: www.centerforresilientchildren.org.

Masten AS, Tellegen A (2012). Resilience in developmental psychopathology: Contributions of the Project Competence Longitudinal Study. Dev Psychopathol. 24(2): 345-361. https://doi.org/10.1017/s095457941200003x.

McEwen CA, Gregerson SF (2019). A critical assessment of the adverse childhood experiences study at 20 years. Am J Prev Med. 56(6): 790-794. https://doi.org/10.1016/j.amepre.201 8.10.016.

Murray DW, Rosanbalm K, Christopoulos C (2016). Self-regulation and toxic stress report 3: A comprehensive review of self-regulation interventions from birth through young adulthood. FPG Child Development Institute. Washington, DC. Available at: https://fpg.unc.edu/node/8278 (Accessed: 7 July 2020).

Narayan AJ, Rivera LM, Bernstein RE, Harris WW, Lieberman AF (2018). 
Okwori et al./ Adverse Childhood Experiences and Resiliency among College Students

Positive childhood experiences predict less psychopathology and stress in pregnant women with childhood adversity: A pilot study of the benevolent childhood experiences (BCEs) scale. Child Abuse and Negl. 78: 1930. https://doi.org/10.1016/j.chiabu.2017.09.022.

National Scientific Council on the Developing Child (2015). Supportive relationships and active skill-building strengthen the foundations of resilience. Available at: www.developingchild.net.

O'Connell A (2011). The cumulative (proportional) odds model for ordinal outcomes', in logistic regression models for ordinal response variables. SAGE Publications. 28-54. https://doi.org/10.4135/9781412984812.n4.

Pérez-Zepeda MU, Belanger E, Zunzunegui MV, Phillips S, Ylli A, Guralnik J (2016). Assessing the validity of selfrated health with the short physical performance battery: Across-sectional analysis of the international mobility in aging study. PLoS ONE. 11(4): eo153855. https://doi.org/10.1371/journal.pone.0153855.

Schafer JL (1999). Multiple imputation: a primer. Stat Methods Med Res. 8(1): 3-15. https://doi.org/10.1177/096228029900800102.

Shonkoff JP, Garner AS, Committee on Psychosocial Aspects of Child and Family Health; Committee on Early Childhood, Adoption, and Dependent
Care; Section on Developmental and Behavioral Pediatrics (2012). The lifelong effects of early childhood adversity and toxic stress. Am Academy of Pediatrics, 129(1): e232e246. https://doi.org/10.1542/peds.2011-2663.

Smith BW, Epstein EM, Ortiz JA, Christopher PJ, Tooley EM (2013). In: Prince-Embury S, Saklofske D. (eds) Resilience in Children, Adolescents, and Adults. The Springer Series on Human Exceptionality. Springer, New York, NY. https://doi.org/10.1007/978-1-4614-4939-3_13

Talbot JA, Szlosek D, Ziller EC (no date) Adverse Childhood Experiences in Rural and Urban Contexts. Portland, ME: University of Southern Maine, Muskie School of Public Service, Maine Rural Health Research Center.

Traub F, Boynton-Jarrett R (2017). Modifiable resilience factors to childhood adversity for clinical pediatric practice. Pediatrics. 139(5): e20162569 https://doi.org/10.1542/peds.20162569.

Young-Wolff KC, Alabaster A, McCaw B, Stoller N, Watson C, Sterling S, Ridout KK, Flanagan T (2019). Adverse childhood experiences and mental and behavioral health conditions during pregnancy: The role of resilience. J Womens Health (Larchmt). 28(4): 452-461. https://doi.org/10.1089/jwh.2018.7108. 